CZU:811.135.1'282.2

https://doi.org/10.52505/filomod.2021.15.35

\title{
POSIBILITĂŢI DE ABORDARE A TEXTELOR DIALECTALE DIN PERSPECTIVA TEORIEI COŞERIENE A VARIAŢIEI LIMBII

\author{
LILIANA POPOVSCHI
} \\ Institutul de Filologie Română „B. P.-Hasdeu” al MEC
}

Rezumat. Textele dialectale reprezintă surse valoroase pentru diverse cercetări privind limba română. Ele sunt deosebit de utile pentru studierea fenomenului variaţiei limbii, fiind ilustrative pentru cele trei mari tipuri de varietate care există in sincronie, conform teoriei coşeriene: varietatea diatopică, varietatea diastratică, varietatea diafazică. Deşi au fost utilizate, mai cu seamă, pentru relevarea diferenţelor teritoriale ale limbii, ele furnizează date importante şi pentru cercetările de sociolingvistică şi de stilistică a limbii. În realizarea concretă a limbii, surprinsă de textele dialectale, sincronia interferează cu diacronia, care este un alt tip de varietate glotică.

Cuvinte-cheie: texte dialectale, Eugen Coşeriu, variaţia limbii, varietate diatopică, varietate diastratică, varietate diafazică, varietate diacronică, limbă comună, limbă literară.

Abstract. Dialectal texts are valuable sources for research on Romanian language. They are especially useful for the study of the phenomenon of language variation, being illustrative of the three main types of variety that exist in synchrony, according to Coseriu's theory: diatopic variety, diastratic variety, diaphasic variety. Although they were used mostly to reveal the territorial differences of the language, they also provide important data for sociolinguistic and stylistic research. In the concrete realization of language, captured by dialectal texts, synchrony interferes with diachrony, which is another type of variety.

Keywords: dialectal texts, Eugen Coseriu, language variation, diatopic variety, diastratic variety, diaphasic variety, diachronic variety, common language, standard language.

Textele dialectale oferă un material de studiu foarte bogat, abordabil din numeroase puncte de vedere. Fiind, în primul rând, „documente lingvistice”, ele reprezintă surse valoroase pentru cele mai diverse cercetări privind limba română. În cele ce urmează, vom încerca să evidenţiem posibilităţile de abordare a textelor dialectale din perspectiva teoriei lui Eugen Coşeriu referitoare la variaţia limbii.

Amintim că în viziune coșeriană „o limbă istorică” include, în afară de limba comună, mai mult sau mai puţin unitară, trei mari tipuri de 
varietate: varietatea diatopică (varietate în spaţiul geografic), varietatea diastratică (varietate între straturile socioculturale ale unei comunităţi de vorbitori), varietatea diafazică (varietate în funcţie de scopurile expresive şi circumstanţele comunicării). Varietăţile formează structura externă a unei limbi istorice, numită şi arhitectura limbii. Fiecare varietate reprezintă un ansamblu de sisteme omogene, unitare, respectiv unităţile sintopice, care sunt dialectele, unitățile sinstratice - nivelurile de limbă, unităţile sinfazice - stilurile de limbă. Studiul varietăţii diatopice, al unităţilor sintopice şi al relaţiilor dintre ele formează obiectul dialectologiei, studiul varietăţii diastratice, al unităţilor sinstratice şi al relaţiilor dintre ele formează obiectul sociolingvisticii, iar studiul varietăţii diafazice, al unităţilor sinfazice şi al relaţiilor dintre ele constituie obiectul stilisticii limbii. Termenii diafazic şi sinfazic au fost puşi în circulaţie de către Eugen Coşeriu, pe când cei referitori la celelalte două tipuri de varietate au fost preluaţi de la lingvistul norvegian Leiv Flydal, care, la rândul său, i-a creat după modelul termenilor saussurieni diacronie şi sincronie (Coşeriu, 1994a, p. 57-60).

Scopul principal al culegerii textelor dialectale este, bineînţeles, ilustrarea variaţiei diatopice a limbii române şi acumularea de fapte necesare pentru studierea unităţilor ei teritoriale, ceea ce devine un imperativ în ultimul timp din cauza acţiunii nivelatoare a limbii literare sau, în cazul graiurilor româneşti din medii aloglote, a consecinţelor politicii de deznaţionalizare, duse de statele în care populaţia românească a fost nevoită să evolueze, în virtutea împrejurărilor istorice (Marin et al., 2016, p. 7). Materialul înregistrat în timpul anchetelor relevă diferențele existente între diversele zone ale arealului dacoromân: variante fonetice, ce se deosebesc fie prin componenţa fonematică (piatră - pt'atră - pkatrâ - katrâ), fie prin distribuţia fonemelor (pînteĉe pîncete), fie prin accent (piéliţă - pieliţă); variante morfologice, ce aparţin unor paradigme diferite (obraz, obraji - obraz, obrazuri); variante lexicale, desemnând aceeaşi noţiune (varză-curechi). Textele sunt utile îndeosebi pentru studierea fenomenelor de sintaxă. Importanţa lor pentru cercetările din acest domeniu este confirmată de valoroasele monografii şi studii consacrate sintaxei părţilor de vorbire, sintaxei propoziţiei, coordonării şi subordonării în frază, reuşindu-se chiar identificarea unor ,arii dialectale sintactice” (Dumistrăcel, 1993, p. XXI; Dumistrăcel, 2014, p. 120-122). Atestând trăsăturile fonetice, lexicale, gramaticale ale graiurilor din localităţile anchetate, textele dialectale fac posibilă studierea unui şir de probleme dialectologice: precizarea ariilor de răspândire a particularităţilor dialectale şi, în consecinţă, delimitarea mai exactă a unităţilor geografice ale limbii, identificarea trăsăturilor care le individualizează şi care le apropie, determinarea schimbărilor ce au loc în prezent în graiuri sub influenţa limbii literare, a altor graiuri sau limbi de contact, a specificului dezvoltării graiurilor periferice şi insulare ale limbii române în comparaţie cu cele centrale, stabilirea direcţiei evoluţiei graiurilor româneşti, a caracterului lor arhaic sau inovator etc.

Deşi au fost utilizate, mai cu seamă, pentru studierea diferenţelor teritoriale ale limbii, textele dialectale sunt ilustrative şi pentru celelalte două 
tipuri de varietate. Subliniem, în acord cu teoria coşeriană, că fiecare dintre unităţile omogene ale limbii este unitară numai dintr-un punct de vedere: un dialect e unitar numai din punct de vedere spaţial, însă prezintă diferenţe diastratice şi diafazice; un nivel de limbă prezintă diferenţe diatopice şi diafazice; un stil de limbă prezintă diferenţe diatopice şi diastratice (Coşeriu, 1994a, p. 57-60). Dacă ne referim la discurs, e necesar să reţinem că ,nu vorbim numai cu omogeneitatea, vorbim şi cu varietatea limbii şi când, de la lingvistica descriptivă a limbilor, trecem la lingvistica textuală şi la interpretarea textelor, atunci constatăm că în text nu avem numai o singură gramatică omogenă, monolitică, ci găsim şi această varietate, şi găsim că vorbitorii întrebuinţează conştient, nu numai inconştient, într-un fel de amestec de limbi, şi varietatea de limbă..." (Coșeriu, 1994a, p. 62). Așadar, orice text dialectal, ca realizare concretă a unui grai local, reflectă în acelaşi timp poziţia socială, vârsta, nivelul de instruire şi de cultură, atitudinile, emoţiile vorbitorului, modul său individual de întrebuinţare a mijloacelor de expresie, furnizând date pentru cercetările de sociolingvistică şi stilistică a limbii.

Noi perspective de interpretare a datelor dialectale deschid textele dialectale înregistrate după iniţierea anchetelor pentru elaborarea Noului atlas lingvistic român (NALR) în vederea constituirii Arhivei fonogramice a limbii române (AFLR). Spre deosebire de primele corpusuri de texte dialectale, acestea pun la dispoziţia cercetătorilor material comparabil nu numai din punctul de vedere al variaţiei teritoriale a limbii, ci şi din punctul de vedere al variaţiei sociale şi al celei stilistice, deoarece s-a lucrat cu o metodă îmbunătăţită în ceea ce priveşte numărul de informatori din fiecare localitate, criteriile de selectare a informatorilor şi tipologia textelor (Cazacu, 1967, p. XVIII-XIX).

S-a acceptat ca principiu necesitatea pluralităţii informatorilor, pentru a surprinde, într-o comunitate dată, particularităţile de grai pe sexe, generaţii şi nivele culturale şi a înlesni astfel studierea diferenţierii graiurilor româneşti în funcţie de variabilele sociale. Una dintre primele abordări ale textelor dialectale din acest punct de vedere aparţine lui Boris Cazacu. Prezentăm unele observaţii ale lingvistului român. Comparând relatările despre prelucrarea cânepii a două femei din aceeaşi localitate cu acelaşi nivel de instruire (4 clase), dar aparţinând unor generaţii diferite (75 şi 37 de ani), autorul constată că vocabularul informatoarei mai tinere are un caracter neologic mai pronunţat. Deosebirile de grai dintre generaţii devin şi mai izbitoare, dacă informatorii au nivel cultural diferit. Dat fiind că persoanele mai în vârstă au avut acces limitat la educaţie, de obicei factorul nivel cultural ,acţionează convergent cu factorul generaţie". În ceea ce priveşte exprimarea bărbaţilor, autorul remarcă o mai puternică influenţă a limbii standard, manifestată mai ales în domeniul lexicului şi al frazeologiei, în cazul celor ce au efectuat stagiul militar şi au avut deplasări mai frecvente în centre urbane şi contacte sociale mai intense cu vorbitorii din alte comunităţi (Cazacu, 1976, p. 296-298).

În cazul înregistrărilor efectuate în medii aloglote, principiile metodologice generale au fost adaptate la situaţia de pe teren. De multe 
ori, unicul criteriu de selectare a informatorilor a fost cel al cunoaşterii idiomului matern şi, întrucât doar generaţia vârstnică mai utilizează limba română, subiecţii aleşi aparţin doar acestei categorii de vârstă. Adesea, au fost înregistraţi mai mulţi membri ai aceleiaşi familii, în general soţ şi soţie, constatându-se deosebiri între soţi privind gradul de conservare a graiului matern (Marin et al., 2016, p. 11-12; TD-Ucraina, p. 35-36). Deşi metodologia culegerii textelor recomandă ca informatorii să corespundă nivelului mediu de instruire, în anumite localităţi ,,unde româna literară este insuficient cunoscută de intelectualitatea rurală, au fost înregistraţi şi subiecţi provenind din pătura cultă, cum ar fi învăţători pensionari sau funcţionari" (Marin et al., 1998, p. 70).

Textele culese în localităţile din afara graniţelor României constituie însă surse importante pentru studierea unei alte probleme de ordin sociolingvistic, evidenţiate de Eugen Coşeriu, cea referitoare la: „«statutul» şi relaţiile socioculturale ale diferitelor limbi din cadrul unei comunităţi" (Coşeriu, 1994b, p. 144). Cercetările efectuate demonstrează că în majoritatea zonelor, cu rare excepţii, graiurile românești sunt pe cale de disoluţie. Limba română şi-a redus treptat funcţiile sociale în favoarea limbilor oficiale din ţările respective, restrângându-şi, în general, sfera de utilizare la mediul familial, iar tinerii au pierdut necesitatea, apoi şi deprinderea de a o mai vorbi (Marin et al., 2016, p. 7-11). Elocventă în acest sens este remarca unei informatoare: iắca a

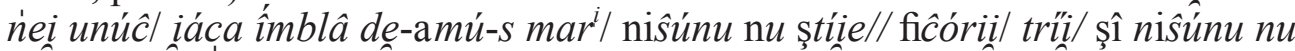
ştíie/l tăt o kicát// [...] prăpădit/ prăpădím noi límbal/ (TD-Ucraina, p. 537). Printre cauzele care au determinat generaţia tânără să-şi abandoneze idiomul matern, pot fi numite următoarele: presiunea exercitată de prestigiul cultural, social şi politic al limbilor oficiale, lipsa învăţământului în limba română, statutul de limbă minoritară al acesteia, nevoia de integrare socială, dorinţa de promovare socială etc. (TD-Ucraina, p. 33). În unele zone, chiar şi cei vârstnici reuşesc să utilizeze cu mare dificultate câteva cuvinte în limba maternă (TDUcraina, p. 31). În vorbirea celor ce se exprimă relativ fluent în limba română, se constată totuşi modificări, datorate contactului cu alte limbi, dar mai ales

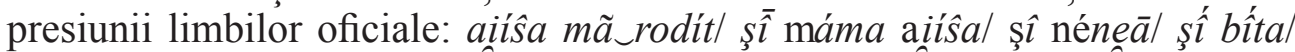
şî tétea...// (TD-Ucraina, p. 359). Interferenţele, împrumuturile, alternanţa şi amestecul a două coduri (grai matern - limbă oficială) ilustrează „fenomenul dislocării mecanismelor sinergetice ale limbii române din diaspora" și denotă „o degradare progresivă a mecanismelor de autoorganizare şi autoreglare” (Pavel, 2003, p. 89), prefigurând dispariţia ei iminentă.

Conform unui alt principiu metodologic, au fost culese texte tematice, obţinute ca răspuns la întrebările anchetatorului cu privire la îndeletnicirile rurale, tradiţii, obiceiuri etc., şi texte libere, comunicate de informatori din proprie iniţiativă. Deosebirea între cele două categorii de texte este, în primul rând, de natură stilistică: textele tematice, în general descriptive, aparţin limbajului popular nonartistic, nuanţat tehnic, iar textele libere, de regulă narative, relatând evenimente, întâmplări din viaţa informatorilor sau din istoria satelor, aparţin stilului artistic popular; primele ,pot fi raportate la 
stilul ştiinţific al limbii literare, iar celelalte reflectă, în limite diferite şi cu nuanţe, stilul artistic, chiar dacă nu este vorba de naraţiuni în accepţiunea curentă a acestui termen", susţine Stelian Dumistrăcel (Dumistrăcel, 1993, p. XV-XIX). În vorbire, cele două stiluri se concretizează într-o multitudine de forme în funcţie de modul individual de exprimare şi de predispoziţiile comunicative ale fiecărui informator, astfel încât, după cum afirmă Grigore Brâncuş, în corpusurile de texte dialectale „stilul vorbit dialectal” apare „în toată complexitatea lui” (Brâncuş, 1969, p. 185), cu întreaga gamă de mărci distinctive la nivel fonetic, lexical, gramatical, discursiv şi pragmatic: pronunţări regionale, modificări fonetice cauzate de interdependenţa sunetelor în lanţul vorbirii sau de un debit verbal rapid, accente afective şi variaţii de înălţime a intonaţiei, cuvinte şi expresii populare, augmentative şi, mai cu seamă, diminutive, forme gramaticale neliterare, diverse mijloace de exprimare a superlativului, repetiţii, interjecţii, deictice, topică afectivă, formule de adresare, substantive în vocativ, verbe la imperativ, enunţuri exclamative şi interogative, enunţuri incomplete, construcţii eliptice, discontinuitate sintactică şi alte greşeli de exprimare (anacolutul, dezacordul etc.), subordonate omogene, juxtapunerea propoziţiilor simple, utilizarea, pe larg, a conectorilor narativi etc. (Got, 2007, p. 27; Molea, 2016). Prin urmare, textele dialectale oferă o importantă bază documentară pentru studiul oralităţii în varianta sa rustică nonstandard.

În sfera de interes a disciplinelor preocupate de variaţia limbii, aşa cum s-a putut observa mai sus, intră şi relaţia diverselor varietăţi idiomatice cu limba comună sau cu forma ei exemplară - limba literară, care funcţionează de multe ori ca nivel sau ca stil de limbă.

Eugen Coşeriu nota că fiecare vorbitor ,poate realiza şi forme care nu ţin de nivelul, de dialectul lui" şi cunoaşte mai multe stiluri de limbă (Coşeriu, 1994a, p. 61). La ora actuală, datorită intensificării contactelor sociale şi accesului la educaţie al majorităţii populaţiei, vorbitorii posedă cel puţin două sisteme: ,unul, al graiului local şi altul, mai mult sau mai puţin apropiat de cel al limbii literare” (Ionică et al., 1973, p. 27). Mai mult ca atât, ei „au conştiinţa coexistenţei celor două sisteme", atribuindu-le un statut stilistic bine precizat şi făcând apel fie la un sistem, fie la celălalt în funcţie de situaţie, de destinatarul căruia îi este adresat mesajul. Pornind de la datele obţinute în urma unor anchete, efectuate în câteva localităţi ale teritoriului dacoromân, Boris Cazacu încearcă să explice mecanismul schimbărilor ce apar în procesul interacţiunii dintre dialect şi aspectul standard al limbii. Potrivit dialectologului român, coexistenţa şi utilizarea alternativă a celor două sisteme, impusă de contextul situaţional, determină ,apariţia sporadică a unor particularităţi extrasistematice" în raport cu sistemul utilizat în mod curent. Unele elemente dialectale, în special cele care ar putea stânjeni comunicarea în condiţiile vieţii moderne, sunt înlocuite cu corespondentele lor literare, informatorul fiind totuşi conştient de diferenţele ce există între modul său de a vorbi şi cel 
al generaţiei mai în vârstă. Rezultatul interacţiunii dintre aspectul standard şi aspectul regional al limbii, în opinia lui Boris Cazacu, este apariţia unei forme de comunicare intermediare, care poate fi numită interdialect şi care se caracterizează prin eliminarea anumitor particularităţi dialectale şi păstrarea altora, a căror arie de răspândire depăşeşte adesea limitele dialectului respectiv (Cazacu, 1966).

Problema menţionată poate fi studiată cu succes în baza textelor dialectale care atestă trecerea de la registrul dialectal, uzual, la registrul literar, în condiţiile speciale de comunicare pe care le crează ancheta, precum şi elementele noi ce apar în vorbirea purtătorilor de grai sub influenţa limbii

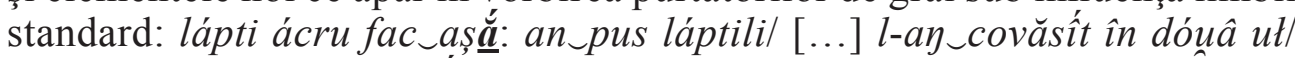

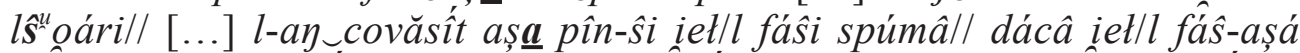
spúmâ mút/ltâ pi dî́nsu/ ápu-i gáta covăsî́t/l an_luát șî l-an_pus númai î́ntr-

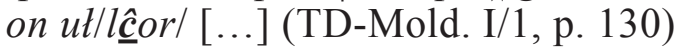

Reflectând modul în care se produce schimbarea în limbă, concurenţa dintre vechi şi nou, textele dialectale confirmă, mai convingător decât alte texte, aserţiunea coşeriană: „se vorbeşte nu numai cu sincronia, ci şi cu diacronia, care este un tip al varietăţii limbii" (Coşeriu, 1994a, p. 63). Cu alte cuvinte, în vorbire aspectele sincronice se împletesc cu cele diacronice, deoarece funcţionarea limbii presupune schimbare continuă, în conformitate cu necesităţile de exprimare.

Celor interesaţi de variaţia diacronică, textele dialectale le oferă un material valoros pentru stabilirea liniei evolutive a faptelor de limbă, atât a celor specifice graiurilor locale, cât şi a celor proprii limbii comune, care are bază dialectală. Se ştie că variantele teritoriale sunt mai conservatoare şi păstrează un număr mai mare de arhaisme, reprezentând faze anterioare în evoluţia limbii comune.

Concluzionând, subliniem că textele dialectale înfăţişează toate formele de manifestare a variaţiei limbii române, deoarece surprind realizarea firească a diverselor ei variante (teritoriale, sociale, stilistice) şi relaţiile lor reciproce în procesul complex al comunicării. Deşi termenul folosit în mod tradiţional pentru a le numi le recomandă drept surse utile pentru descrierea varietăţii diatopice a limbii, ele pot fi valorificate în egală măsură şi pentru studierea celorlalte tipuri de varietate: diastratică, diafazică, diacronică.

\section{Referințe bibliografice:}

1. BRÂNCUŞ, Grigore. [Recenzie la] Texte dialectale. Oltenia. În: Limba română. Bucureşti, 1969, nr. 2, p. 185-186.

2. CAZACU, Boris. Despre noţiunea de, ,interdialect”. În: Studii şi cercetări lingvistice. 1966, nr. 1, p. 13-18.

3. CAZACU, Boris. Prefaţă. În: Texte dialectale. Oltenia, publicate sub redacţia lui Boris Cazacu, de Cornelia Cohuţ, Galina Ghiculete, Maria Mărdărescu, Valeriu Şuteu şi Magdalena Vulpe. Bucureşti, 1967, p. XVII-XXII. 
4. CAZACU, Boris. Aspecte ale variaţiei lingvistice în graiurile munteneşti (pe baza datelor din „Texte dialectale. Muntenia”. I-III). În: Studii şi cercetări lingvistice. 1976, nr. 3, p. 293-299.

5. Coşeriu, 1994a: COŞERIU, Eugen. Arhitectura şi structura limbii. În: Prelegeri şi conferinţe (1992-1993), supliment al publicaţiei „Anuar de lingvistică şi istorie literară”, T. XXXIII, 1992-1993, Seria A, Lingvistică, Iaşi, 1994, p. 49-64.

6. Coşeriu, 1994b: COŞERIU, Eugen. Socio- şi etnolingvistica. Bazele şi sarcinile lor. În: COŞERIU, Eugen. Lingvistică din perspectivă spaţială şi antropologică. Trei studii. $\mathrm{Cu}$ o prefaţă de Silviu Berejan şi un punct de vedere editorial de Stelian Dumistrăcel. Chişinău: Ştiinţa, 1994, p. 129-156.

7. DUMISTRĂCEL, Stelian. Cuvânt înainte: Probleme ale publicării şi ipostaze ale utilizării textelor dialectale ca instrument de cercetare. În: Noul Atlas lingvistic român, pe regiuni. Moldova şi Bucovina. Texte dialectale, volumul I, partea 1, culese de Stelian Dumistrăcel şi publicate de Doina Hreapcă şi Ion-Horia Bîrleanu. Iaşi, 1993, p. VII-XXXI.

8. DUMISTRĂCEL, Stelian. Textele orale în registru dialectal ca bază de date pentru exegeze lingvistice. În: Ion Coteanu - In memoriam. Bucureşti, 2014, p. 119-136. [online] Disponibil: http://www.diacronia.ro/ro/indexing/details/V135 [citat 03.03.2021]

9. GOT, Mioriţa. Stilistica limbii române. Bucureşti, 2007. [online] http://www. colegiumaniucarei.ro/ckfinder/userfiles/files/STILISTICA\%20LIMBII\%20ROMANE\%20 -\%20M_Got.pdf [citat 29.05.2021]

10. IONICĂ, Ion, LĂZĂRESCU, Paul, VULPE, Magdalena. Cu privire la raporturile dintre limba literară şi graiuri. În: Fonetică şi dialectologie. 1973, nr. VIII, p. 19-30.

11. Marin et al., 1998: MARIN, Maria, MĂRGĂRIT, Iulia, NEAGOE, Victorela. Graiuri româneşti din Ucraina şi Republica Moldova. În: Fonetică şi dialectologie. 1998, nr. XVII, p. 69-156.

12. Marin et al., 2016: MARIN, Maria, RADU, Carmen-Ioana, RĂUȚU, Daniela, TIUGAN, Marilena. „Harta sonoră” a graiurilor dacoromâne vorbite în afara graniţelor României. București, 2016.

13. MOLEA, Viorica. Oralitatea în textul publicistic actual românesc. Chişinău, 2016.

14. PAVEL, Vasile. Reconsiderări privind situaţia graiurilor româneşti din Caucaz. În: Limba şi literatura română în spaţiul etnocultural dacoromânesc şi în diaspora. Secţiunea Lingvistică: I. Limbă şi identitate. Editori: Ofelia Ichim, Florin-Teodor Olariu. Iaşi, 2003. [online] http://www.philippide.ro/limba\%20si\%20literatura\%202003/12_Pavel.pdf [citat 14.03.2021]

15. TD-Mold. I/1: Texte dialectale. Supliment la Atlasul lingvistic moldovenesc (ALM), volumul I, partea I, culese de V. Melnic, V. Stati, R. Udler. Chişinău, 1969.

16. TD-Ucraina: MARIN, Maria, MĂRGĂRIT, Iulia, NEAGOE, Victorela, PAVEL, Vasile. Graiuri dacoromâne din sud-estul Ucrainei. Studiu lingvistic. Texte dialectale. Glosar. Bucureşti, 2016.

Notă: Articolul a fost realizat în cadrul proiectului de cercetare 20.80009.1606.01 Valorificarea științifică a patrimoniului lingvistic național în contextul integrării europene, Institutul de Filologie Română „B. P.-Hasdeu” al MEC. 